\title{
Can Virtual Reality Therapy (VRT) be practiced in Traumatic Lower Limb Amputees for balance and gait improvement?
}

\author{
A Saravanamoorthy ${ }^{1 *}$, Sushma Sagar ${ }^{2}$, Subodh Kumar ${ }^{2}$ \\ ${ }^{1}$ Physiotherapist, Physiotherapy Unit, JPN Apex Trauma Centre, AIIMS, New Delhi \\ ${ }^{2}$ Professor, Division of Trauma Surgery and Critical Care, JPN Apex Trauma Centre, \\ AIIMS, New Delhi \\ *Corresponding Author: A Saravanamoorthy, Physiotherapist, Physiotherapy Unit, \\ JPN Apex Trauma Centre, AIIMS, New Delhi
}

DOI: $10.31080 /$ ASOR.2020.03.0143
Received: January 17, 2020

Published: January 29, 2020

(C) All rights are reserved by

A Saravanamoorthy., et al.
Amputation is the surgical removal of the partial or complete limb. It can either be any level of lower limb or any level of the upper limb and can be as a result of the road traffic accident, railway track accident, gunshot injury, earthquakes of significant intensity and terrorism, or carried with medical reasons to improve health status [1]

According to the National Health Interview Survey of USA, in 19961.2 million people were living with an amputee and 185,000 persons undergo upper or lower limb amputations each year [2].

In India on 2017 total Road Traffic Accidents were 4,64,910 out of these Total Number of Persons Injured was 4,70,975 (in numbers) (http://morth.nic.in) Published on Data Portal: 25/04/2019. According to WHO, India has the highest number of road traffic accidents in the world with 16.8 fatal injuries per 100,000 population, and 38.9 non-fatal injuries per 100,000 populations as per the data from 2006. Thus, it can be presumed that traumatic road accidents would be a significant cause of lower limb amputation [3].

The data from AIIMS, Trauma Centre at New Delhi shows that there were 310 lower limb amputations done from the year 2007 to 2014. During this period, the maximum amputations ( $n=68$ ) were done in 2013-2014. Above-knee amputation is the most common among all the levels of lower limb amputations. In the year 2017 \& 2018, the total no. of amputation cases increased respectively 198 \& 206. Among them, there were 152 \& 120 cases of lower limb amputation.

PPeople who undergo lower limb amputation suffer from decreased stability and an altered center of gravity leading to compromise in balance and gait, thus increasing the risk of falling. It also leads to compromise in social activity and causes depression [4] With amputation, the sensory receptors in the lost limb and joints reduce feedback to the brain for decision making during balance and gait. Also, the original control pattern of the brain, i.e., the brain map w.r.t balance and gait become incorrect after the loss of a lower limb [5] 90\% of the patients with lower limb amputees experience Phantom limb sensation. It is the sensation that the missing limb is still present. Majority of these patient experiences pain in this phantom limb called as phantom limb pain [6].

Reorganization of brain map can occur through training and use. $80 \%$ of the power during the gait cycle is through the plantar flexors. Loss of amputee results in reorganization of the plantar flexors. It promotes motor cortex in the brain and spinal cord to shift on the hip flexors of the affected leg to provide forwarding force during gait cycle [5].

Virtual Reality is an inexpensive and interactive system that provides its users with the illusion of entering a virtual world to encourage people with motor disabilities. Gobbetti and Scateni in 1998 stated that "the goal of virtual reality is to put the user in the loop of real-time simulation, immersed in a world that can be both autonomous and responsive to its actions". VR demands focus and attention and can also motivate the user for the activities. Thus, VR stimulates body systems that govern balance and promotes brain mapping $[7,8]$.

In 2011, Benjamin J Darter\& Jason M Wilken presented a case report which described the use of virtual reality (VR)-based gait training program. A 24-year-old man with transfemoral amputation was treated with the intervention of the 3-week gait training program which consisted of 12 sessions of treadmill walking with real-time visual feedback on full-body gait kinematics. Improvement in trunk motion was observed at the post-training test, and improvements in pelvis and hip motion were observed at the 3-week follow-up test. In summary, this case report indicates that the use of the VR environment-based real-time feedback holds great assurance in the rehabilitation of individuals with amputation patients [9]. 
The Xbox Kinect ${ }^{\mathrm{TM}}$ is a Microsoft AVG console which uses the VR technology to enhance the experience of the user. It provides a video gaming system for full-body control of animated virtual characters giving the user an interactive experience and thus can work as a VR based technique to improve balance and gait [10] Also, it has recently been reported that VRT helps in reducing this pain significantly [6].

Technology like this is noninvasive, inexpensive and it can be used to encourage people with motor disabilities to exercise in multiple sessions.

The author feels the virtual reality therapy is effective tool in training the integrated cognitive- motor domain to improve body balance, gait pattern, relief from phantom limb sensation, thus, enhancing the activities of daily life in patients undergoing traumatic lower limb amputation. Further research on this subject shall be rewarding.

\section{Bibliography}

1. Sinha R. "Adjustments to amputation and artificial limb, and quality of life in lower limb amputees". Groningen (2013).

2. Adams P., et al. "Current estimates from the national health interview survey, 1996". Vital and Health Statistics 200 (1999): 1-203.

3. Global status report on road safety. World Health Organisation (2009).

4. Hyland Nannette Wright. "A Comparative Analysis of Two Gait Training Approaches for Individuals with Transtibial Amputation". Seton Hall University Dissertations and Theses (ETDs) (2009): 56.

5. Petrofsky JS and Khowailed IA. "Postural sway and motor control in trans-tibial amputees as assessed by electroencephalography during eight balance training tasks". Medical Science Monitor 20 (2014): 2695-2704.

6. Ambron E., et al. "Immersive Low-Cost Virtual Reality Treatment for Phantom Limb Pain: Evidence from Two Cases". Frontier Neurology 9 (2018): 67.

7. Gobbetti E and Scateni R. "Virtual reality: past, present and future”. In: Riva G, Weiderhold BK, Molinari E, editors, Virtual environments in clinical psychology and neuroscience: methods and techniques in advances patient-therapist interaction. Amsterdam: IOS 58 (1998).

8. Bao X., et al. "Mechanism of Kinect-based virtual reality training for motor functional recovery of upper limbs after subacute stroke". Neural Regeneration Research 8.31 (2013): 2904-2913.
9. Darter BJ and Wilken JM. "Gait training with virtual realitybased real-time feedback: improving gait performance following transfemoral amputation". Physical Therapy 91 (2011): 1385-1394.

10. Vernadakis N., et al. "The effect of Xbox Kinect intervention on balance ability for previously injured young competitive male athletes: a preliminary study". Physical Therapy in Sport 15.3 (2014): 148-155.

\section{Assets from publication with us}

- Prompt Acknowledgement after receiving the article

- Thorough Double blinded peer review

- Rapid Publication

- Issue of Publication Certificate

- High visibility of your Published work

Website: www.actascientific.com/

Submit Article: www.actascientific.com/submission.php Email us: editor@actascientific.com

Contact us: +919182824667 